\title{
Género, poder y lengua en los poemas de Florencia Pinar
}

\section{Gender, Power and Language in Florencia Pinar's Poems}

\author{
LOUISE MIRRER \\ University of Minnesota
}

Con base en el análisis del poema "Destas aves su nación”, de Florencia de Pinar, se observa que las estrategias lingüísticas, el tratamiento al tema femenino y la propia labor en cuanto compositora o lectora son elementos interconectados que las escritoras emplean como medios de resistencia frente al dominio masculino.

Palabras Clave: Florencia Pinar, literatura femenina medieval, feminismo y literatura

Based on the analysis of the poem "Destas aves su nación”, by Florencia de Pinar, we can observed that the linguistic strategies, the treatment of the feminine theme and the work itself as composer or reader are interconnected elements that the female writers use as means of resistance to the male dominance.

KEYWORDS: Florencia Pinar, medieval female literature, feminism and literature

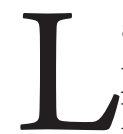

as escritoras castellanas de la Edad Media ocuparon una posición un poco peculiar en el mundo de la producción literaria. Excluidas de la mayoría de las potentes estructuras de la ley y de la doctrina, aparecen totalmente incapacitadas para escribir, actividad que constituía una gran fuente de poder en la Edad Media. Esto, sin duda, explica por qué tan pocas mujeres escritoras emergieron en Castilla durante este periodo, y por qué aquellas mujeres que escribieron lo hicieron de una manera tan defensiva, usando un lenguaje condenado por muchos críticos modernos como ensimismado y cliché. Sin embargo, como lectoras, patronas, y como tema poético, la mujer medieval pudo desempeñar un papel importante. En un artículo reciente sobre la Cárcel de Amor ("The Politics"), Barbara Weissberger 
demuestra la importancia que tenía la mujer en la producción y el consumo de la literatura amorosa del siglo xv. Escrita por un hombre, Cárcel explora el deseo femenino para un público en el cual figuró la mujer en forma prominente - la reina Isabel poseía una copia del texto, y una anécdota del siglo XVI sobre la recepción femenina de la obra comprueba qué popular era entre las lectoras-.

La posición peculiar de la mujer dentro de la dinámica de la producción literaria medieval —es decir, su personificación paradójica de una "doble identidad", como lo ha descrito Stephen Nichols ("Medieval Women") — resultó en un estilo innovador que era, muy frecuentemente, anómalo desde un punto de vista lingǘstico. En este trabajo partimos de la base de que las mujeres escritoras de aquellos siglos tuvieron que recurrir a distintos códigos 96 lingüísticos en sus obras. Desarrollar un lenguaje peculiar "de las mujeres" fue, para ellas, una manera de asegurarse un lugar en los dominios - tanto intelectuales como políticos que por definición las excluyeron-. Nos centramos específicamente en los poemas de Florencia Pinar, en particular, "Destas aves su nación." ${ }^{1}$ Estudiaremos este texto sobre el fondo de otros textos escritos por mujeres durante la época para demostrar la conexión entre el lenguaje peculiar "de las mujeres", el papel más pasivo de la mujer como tema y patrón poéticos, y su participación más activa como escritora y lectora. Analizaremos en particular el uso de ciertos términos que las mujeres escritoras como Pinar usaron para atraer la atención sobre ellas mismas, como ejemplos de mujeres desafortunadas y sufridas. Estudiaremos también la seguridad de Pinar en el registro del lamento y su manipulación de perspectivas múltiples, incluyendo la incorporación renuente del "yo" hablante o poético. Estas particularidades son también características de las obras escritas por mujeres durante la Edad Media. Queremos sugerir, finalmente, que las estrategias lingüísticas específicamente femeninas que hemos mencionado hasta aquí deben ser consideradas como modos de resistencia a la dominación masculina dentro de una cultura en la cual el hombre, rutinariamente, asumió las funciones significativas y representativas de la mujer.

Uno de los poemas atribuidos a Pinar en tres colecciones del Cancionero de los siglos Xv y XVI comienza así:

\footnotetext{
${ }^{1}$ Sobre los poemas atribuidos a Pinar en el Cancionero, véase Broad ("Florencia Pinar"), Deyermond ("Spain's First Women" y "The Worm"), Flores y Flores (The Defiant Muse), Fulks ("The Poet"), Recio ("Otra dama"), Snow (“The Spanish"), y Wilkins ("Las voces").
} 
Destas aves su nación es cantar con alegría, y de vellas en prisión siento yo grave pasión sin sentir nadie la mía.

(Cancionero general)

Desde el principio, el poema es agresivamente femenino incorporando, en su primera estrofa, un esquema de rima que depende exclusivamente del género femenino gramatical — cada verso termina en un sustantivo o pronombre femenino-. También encontramos en estas líneas una articulación particular femenina de la relación entre lo personal y lo institucional. "Nación", por ejemplo, un término justamente localizado en el dominio masculino de poder oficial y político - "conjunto de los habitantes de un país regido por el mismo gobierno", según la primera definición del Diccionario medieval español de Martín Alonso (t. I, 1424) — proyecta aquí una imagen de un mundo sin esencia y un poder imaginario en vez de oficial. No es esto una configuración política legalmente puesta en vigencia que ata a los pájaros, sino un lenguaje privado y personal de una canción alegre.

Mientras es, por supuesto, posible comprender que "nación" significa aquí "linaje" - última definición del término para el siglo xv (Alonso, Diccionario, 1424) — ignorar la más común aparición de la palabra en el discurso que rodea las instituciones públicas del gobierno excluiría efectivamente un significado que Pinar parece estar ansiosa de sugerir. De hecho, su uso del término al hablar de pájaros - una palabra claramente identificada con lo femenino a través del pronombre femenino "ellas" en la tercera línea del textopudo haber sido una manera innovadora de significar el poder femenino y la subjetividad mientras reconoce la coacción política y social que se le impone a la mujer. Esta interpretación está basada en la estructura sintáctica del verso. Corno indica Wilkins ("Las voces"), "nación" es el sujeto gramatical del discurso, pero está desplazado de su posición de sujeto normal por "aves", que aparece en su lugar. Así, "nación", suprimida hasta el final de la línea, pierde algo de la fuerza que podía haber recibido como sujeto, y "aves", que aparece en la posición de sujeto aunque gramaticalmente no cumple la función de sujeto, gana una importancia que, de otra manera, no hubiera tenido.

Así como el discurso cambia, sintácticamente, su énfasis de "nación" como sujeto a "aves" con su canto alegre, el significado feminizado de "nación" dado por Pinar cambia el énfasis del mundo público y masculino de las instituciones a un mundo femenino de emociones personales y privadas 
(canción, por ejemplo). Pero Pinar, en la primera estrofa, explícitamente rehúsa hacer que los "pájaros" sean el verdadero sujeto del discurso. La hipótesis del derecho de las mujeres a "cantar" —o a hablar o a escribir — en una cultura que hizo del silencio una convención femenina no pudo garantizar su subjetividad en la poesía amorosa. Esto queda claro en el gran contenido poético del Cancionero en el cual aparece a menudo la mujer como tema poético dentro de la situación amorosa, pero no como sujeto hablante. ${ }^{2}$

No es, pues, sorprendente que en este contexto se encuentre que Pinar afirme su propia subjetividad en el poema con reserva, ofreciendo la expresión de su sentimiento personal, "siento yo grave passión", muy tarde en la estrofa. (Además, de los tres poemas escritos por Pinar y preservados en los Cancioneros, este es el único que presenta un "yo" hablante en el texto). Aun cuando Pinar afirma su subjetividad en el discurso del texto, su "yo" hablante parece hablar más desde el punto de vista de la tradición de la mujer de posición marginada como objeto en la poesía amorosa, que desde una posición activa al hablar como agente en una situación amorosa. Su voz, declara, no es escuchada por nadie - "siento yo grave passión/ sin sentir nadie la mía"-. Su mudez es efectiva — callada como el árbol en la muy citada pregunta filosófica "¿isi un árbol cae en el bosque y nadie está ahí para oírlo caer, crea el árbol algún sonido?”- Aún más, aquí también existe un ejemplo de la identidad doble de la mujer en el mundo medieval de la producción literaria que tratamos al principio de este trabajo. Mientras que la subjetividad de Pinar en el poema puede ser oscurecida por su silencio en una sociedad que rehúsa autorizar la voz femenina, su acto de escribir el texto y la preservación de su texto en las colecciones del Cancionero demuestran que la mujer pudo $-\mathrm{y}$ de hecho lo hizo- resistir la realidad histórica que le negaba el acceso a las modalidades del discurso público.

Semejante al caso de otras mujeres escritoras medievales (la Condesa de Dia del siglo XII es un ejemplo; Leonor López de Córdoba es otro), Pinar hace de su texto un espejo con género que se enfoca en la división sexual. La tensión entre el hombre y la mujer reflejada en la primera estrofa a través de su lectura feminizada de un término convencional marcado por el dominio masculino (por ejemplo, "nación") se refuerza en la segunda estrofa con su revelación de la agresión del hombre contra la mujer en la única referencia al hombre del texto:

\footnotetext{
${ }^{2}$ Para la incorporación del sujeto hablante femenino en la poesía del Cancionero, véase Whetnall ("Lírica femenina").
} 


$$
\begin{aligned}
& \text { Ellas lloran, que se vieron } \\
& \text { sin temor de ser cativas, } \\
& \text { y a quien eran más esquivas, } \\
& \text { essos mismos las prendieron. }
\end{aligned}
$$

El tema de los pájaros mantenidos en cautiverio por aquellos que los apresaron ha sido ligado por Alan Deyermond al uso de la imaginería de la caza que se emplea en muchos otros textos medievales. Refiriéndose al título del poema, que dice "Otra canción de la misma señora a unas perdizes que le embiaron bivas", enfatiza una conexión entre las imágenes del poema y la sección del bestiario medieval relacionado con las perdices. Deyermond razona que la elección de Pinar de este pájaro en particular como símbolo central de su poema funciona para identificar los instintos del poeta con aquellos descritos por el bestiario y más gráficamente expresados en su declaración que tanto atormenta el deseo a las hembras que aun si el viento trae el olor de los machos, estas quedarán embarazadas solamente por su olor. ${ }^{3}$

La interpretación de Deyermond sugiere que el poema se refiere al deseo sexual de la mujer. Pero la duda acerca del título del texto - esto es, si fue creado por Pinar o simplemente añadido por un redactor - reconocida por Deyermond en una nota ("Spain's First Women”, 47 nota 34) y discutida a su vez por Wilkins ("Las voces", 127), tiende a descentrar la perdiz como imagen principal del poema, particularmente cuando Pinar habla solamente de "aves" y no de "perdices" en el contenido de su obra. Si el poema verdaderamente trata del deseo sexual de la mujer, como sugiere Deyermond, no es sin duda el mismo concepto del deseo femenino tratado en la literatura amorosa creada por hombres y comprendido en la transparentemente masculinista ilustración del bestiario de cómo las perdices hembras obtienen satisfacción sexual. (Tal concepto ha sido descrito - con ironía - por Luce Irigaray como el anhelo de la mujer de ser no solamente, en el sentido freudiano, el objeto del deseo, sino el objeto del deseo del hombre [Speculum, 32]). La mujer, en este contexto, quiere ser el sujeto deseante - no el objeto de las fantasías de los hombres acerca de ellas- Esto explica sus desprecios anteriores por aquellos que las mantuvieron cautivas y su tristeza al encontrarse como objetos del amor, en vez de agentes en la situación amorosa. (Podemos comprender

3 "Desire torments the females so much that even if a wind blows toward them from the males they become pregnant by the smell" (Deyermond, "Spain's First Women”, 47), El crítico cita a T. H. White (The Book of Beasts, Being a Translation from a Latin Bestiary of the Twelfth Century, London: Jonathan Cape, 1954, 137).

Medievalia 50, 2018, pp. 95-103 
aquí que la palabra "esquivas” significa "desdén”, un significado que guarda una relación con el uso repetido del término en otro de los poemas de Pinar, “¡Ay!, que ay quien más no bive”).

La cuestión de tomar una iniciativa sexual o buscar una fantasía erótica, propuesta, creemos, tanto en el simbolismo de la canción alegre del pájaro como en la descripción de su desdén por aquellos quienes las mantienen cautivas, es rápidamente pasada por la expresión simbólica de la privación de la mujer, como objeto del amor, aun de los medios de buscar activamente satisfacción sexual. Así pues, cuando los pájaros finalmente encuentran su manera de afirmación personal en la segunda estrofa del poema-aquí aparecen como sujetos gramaticales del discurso- el texto se centra directamente en su opresión: "Ellas lloran que se vieron/ sin temor de ser cativas". Aquí, 100 de nuevo, aparece la condición paradójica de la mujer. Como en el caso de muchas mujeres escritoras (por ejemplo, Leonor López de Córdoba y Teresa de Cartagena en Castilla, Margery Kempe en Inglaterra y Madame de Gournay en Francia), la frustración de Pinar como sujeto y su posición marginal en la cultura dominante de su época la conduce a buscar autorización presentándose como ejemplo de una mujer desafortunada y sufrida — una advertencia a otras mujeres contra el engaño, como Barbara Fulks lo ha puesto en su artículo sobre otro de los poemas de Pinar, "Ell amor ha tales mañas”. El tema de la mujer sufrida es, por supuesto, afirmado y reafirmado en el estribillo del poema: “[...] y de vellas en prisión/ siento yo grave passión”."

El lamento de Pinar, "Sus nombres mi vida son/ que va perdiendo alegría”, ofrece una evidencia más del enfoque del poema en la división sexual y en el derecho de la lucha de la mujer por la subjetividad. A pesar de que Pinar ligue explícitamente los nombres de los pájaros a su propia vida y a su propia pérdida progresiva de subjetividad, no acierta a nombrar los pájaros. Como hace notar Mieke Bal en su estudio del Libro de los Jueces, la anonimidad, referente a las mujeres, es frecuentemente una metáfora para la mudez. La expresión poética de Pinar de su vida, "Sus nombres mi vida son”, restablece el tema del silencio de la mujer como también su predicamento (o situación difícil o conflictiva) en una realidad histórica que insistió en ello. El verso también revierte sobre la subjetividad paradójica de la mujer en la frase de apertura de la estrofa, "Ellas lloran". Llorar refiere, por excelencia, al son (y aquí creo que existe un juego de palabras con el verbo, "son" de "Sus nombres mi vida son") de la respuesta de las mujeres escritoras medievales al diálogo de desigualdad que caracteriza su cultura.

\footnotetext{
${ }^{4}$ Recio nos ha recordado en su trabajo sobre Pinar que "en la canción el estribillo es la parte en que se fija el tema” ("Otra dama”).
} 
Seguramente, llorar es un distintivo de la intervención de las mujeres escritoras medievales en el dominio público. Las lágrimas de Margery Kempe (The Book), por ejemplo, se derraman copiosamente en los espacios públicos de las iglesias y los pueblos, donde su voz a menudo fue violentamente reprimida.

Tanto la palabra "aves", conectada con la mujer dentro del texto, como la palabra "perdices", que se menciona en el título del poema, son sexualmente $y$, en el caso de "perdices", textualmente, ambiguas. De ninguno de los términos puede deducirse biológicamente el sexo, aunque ambos están codificados gramaticalmente en el género femenino. No es mi intención resolver las diferencias entre los críticos que ven las perdices como símbolos centrales respecto a la interpretación del poema, y aquellos que no lo ven de este modo. ${ }^{5}$ Pero me gustaría señalar que el uso de uno, o de ambos, términos en el texto motiva una interpretación (aun si ocurriese solamente en la mente de un redactor en el caso de las "perdices") basada en la posibilidad de incluir la presencia masculina en un espacio femenino. Así, dentro del control lingüístico del texto, la diferencia sexual se explora a la luz de la realidad histórica, donde la lógica masculina prevalece $y$, de acuerdo con el poder imaginativo peculiar de la lengua, donde la alteridad se preserva a través de los términos gramaticalmente femeninos, pero sexualmente bivalentes. Stephen Nichols, quien ha estudiado a las mujeres escritoras medievales de la literatura amorosa en Francia, encuentra un fenómeno relacionado al anterior. Razona que, en escritoras del siglo XIII como Héloise, la Condesa de Dia, y las presumibles autoras de las "chansons de toile", se encuentra el reconocimiento de una verdad fundamental acerca del amor y sus relaciones con lo femenino

\footnotetext{
${ }^{5}$ Ejemplos de los diferentes puntos de vista se encuentran en Recio, quien declara la importancia de la perdiz respecto al tema del poeta cautivo: "Aparte de la cuestión sexual y lo erótico, lo que interesa es que se trata del poeta en prisión, el poeta cautivo. El poema está expresado de una manera en la que el símbolo de la perdiz [... ] lleva a ese sentido de poema 'manido' o 'monótono' con que se ha tachado a la poesía de cancionero" ("Otra dama”, 333). Broad, quien ve el mundo simbólico del poema modulado por el simbolismo tradicional de la perdiz, y quien dice que éste es un modo de relacionar la emoción menos privada de la compasión con los sentimientos más profundos y personales del poeta: "Aquí la imagen [...] es la relación de un causante de emoción para evocar otro; es una presentación de dos sentimientos paralelos para sugerir una profundidad de emoción que sería difícil de expresar directamente" ("Florencia Pinar", 31). Y Wilkins, quien ve el poema como una expresión de la opresión de las mujeres durante la Edad Media y quien cree que el título del poema, que contiene su única referencia a la perdiz, probablemente fue añadido por un redactor. Para Wilkins, las aves, y no las perdices, son el símbolo central del texto: "Es frecuente que gente oprimida use imágenes pequeñas - como un ave o un gusano. Es bien posible ver estos animales como símbolos de la opresión sistemática en que vivía Florencia Pinar" ("Las voces”, 129).
}

Medievalia 50, 2018, pp. 95-103 
("Medieval Women", 93). Este reconocimiento anticipa lo que Emmanuel Levinas, el filósofo del siglo $\mathrm{xx}$, ha expresado como "le pathétique de l'amour"-la expresión patética del amor que reposa en la dualidad infranqueable del ser (Le Temps, 78, véase también Nichols, "Medieval Women", 93-94) —. Como estas mujeres francesas medievales, Florencia Pinar pudo haber tratado de hablar de amor no simplemente desde una posición de objeto del amor o de sujeto, sino también desde una posición más allá de la separación, "beyond the divide" (Nichols, "Medieval Women", 94).

\section{Bibliografía}

102 Alonso, Martín, Diccionario medieval español, t. I, Salamanca: Universidad Pontificia de Salamanca, 1986.

BAL, Mieke, Death and Dissymetry: The Politics of Coherenc in the Book of Judges, Chicago: University of Chicago Press, 1988.

Broad, Peter, "Florencia Pinar y la poética del Cancionero", en Nora Erro-Orthmann y Juan Cruz Mendizabal (eds.), La Escritora Hispánica, Miami: Ediciones Universal, 1990, 26-35.

Cancionero general recopilado por Hernando del Castillo [Valencia, 1511], ed. de Antonio Rodríguez-Moñino, Madrid: Real Academia Española, 1958.

Deyermond, Alan D., "Spain's First Women Writers", en Beth Miller (ed.), Women un Hispanic Literature, Berkeley: University of California Press, 1983, 27-53.

Deyermond, Alan D.,, "The Worm and the Partridge: Reflections on the Poetry of Florencia Pinar", Mester, 7, 1978, 3-8.

Flores, Ángel y Kate Flores, The Defiant Muse: Hispanic Feminist Poems from the Middle Ages to the Present, New York: The Feminist Press, 1986.

Fulks, Barbara, “The Poet Named Florencia Pinar”, La Corónica, 18:1, 1989, 33-43. IrIGAY, LuCE, Speculum of the Other Woman, trad. Gillian C. Gill, Ithaca: Cornell University Press, 1985.

Kempe, Margery, The Book of Margery Kempe, trad. W. Butler-Bowdon, London: Jonathan Cape, 1936.

Levinas, Emmanuel, Le Temps el l'autre, $2^{\mathrm{a}}$ ed., Paris: Quadrige-Presses Universitarires de France, 1985.

Nichols, Stephen G., "Medieval Women Writers: Aisthesis and the Powers of Marginality”, Yale French Studies, 75, 1988, 77-94.

Recio, Roxana, "Otra dama que desaparece: la abstracción retórica en tres modelos de canción de Florencia Pinar", Revista Canadiense de Estudios Hispánicos, 16:2, 1992, 329-339. 
Snow, Joseph, “The Spanish Love Poet: Florencia Pinar”, en Katharina M. Wilson (ed.), Medieval Women Writers, Athens: University of Georgia Press, 320-382.

Weissberger, Barbara F., “The Politics of Cárcel de Amor", Revista de Estudios Hispánicos, 26, 1922, 307-326.

Whetnall, Jane, "Lírica femenina in the Early Manuscript Cancioneros", en Salvador Bacarise, Bernard Bentley, Mercedes Claraso y Douglas Gifford (eds.), What's Past in Prologue: A Collection of Essays in Honour of L. J. Woodward, Edinburgh: Scottish Academic Press, 1984, 138-175.

Wilkins, Constance, L., "Las voces de Florencia Pinar”, en Rosa E. Penna y María A. Rosarossa (eds.), Studia Hispanica Medievalia II, Buenos Aires: Universidad Católica Argentina, 1990, 124-130. 
